\title{
Phenolic Constituents from Fallopia multiflora (Thunberg) Haraldson
}

\author{
Thi Thoa Nguyen, ${ }^{1,2,3}$ Thanh Binh Pham, ${ }^{2}$ Nguyen Phuong Thao $\left(\mathbb{D},{ }^{2}\right.$ Nguyen Hai Dang, ${ }^{1,2}$ \\ Van Hung Nguyen, ${ }^{2}$ Van Cuong Pham, ${ }^{2}$ Chau Van Minh, ${ }^{2}$ Quang Hai Tran, ${ }^{3}$ \\ and Nguyen Tien Dat $\mathbb{D}^{1,4}$ \\ ${ }^{1}$ Graduate University of Science and Technology, Vietnam Academy of Science and Technology (VAST), 18-Hoang Quoc Viet, \\ Cau Giay, Hanoi, Vietnam \\ ${ }^{2}$ Institute of Marine Biochemistry, VAST, 18-Hoang Quoc Viet, Cau Giay, Hanoi, Vietnam \\ ${ }^{3}$ Faculty of Chemical Technology, Hanoi University of Industry, 298-Cau Dien, Bac Tu Liem, Hanoi, Vietnam \\ ${ }^{4}$ Center for Research and Technology Transfer, VAST, 18-Hoang Quoc Viet, Cau Giay, Hanoi, Vietnam
}

Correspondence should be addressed to Nguyen Tien Dat; ngtiend@imbc.vast.vn

Received 29 May 2018; Accepted 11 July 2018; Published 6 August 2018

Academic Editor: Lutfun Nahar

Copyright (C) 2018 Thi Thoa Nguyen et al. This is an open access article distributed under the Creative Commons Attribution License, which permits unrestricted use, distribution, and reproduction in any medium, provided the original work is properly cited.

\begin{abstract}
Four naphtolic glycosides (1-4), three anthraquinones (5-7), two stilbenes (8-9), one benzyl glycoside (10), and one flavonoid (11) were isolated from the roots of Fallopia multiflora. The new compounds were elucidated to be 6-hydroxymusizin 8-O- $\alpha$-D-apiofuranosyl$(1 \rightarrow 6)-\beta$-D-glucopyranoside (1) and 6-methoxy-3-methyl-1,6,8-trihydroxy-2-naphthoic acid 8-O- $\beta$-D-glucopyranoside (3). Compound 3 could be an important marker for chemotaxonomy of F. multiflora. Benzyl gentiobioside (10) was isolated for the first time from the family Polygonaceae.
\end{abstract}

\section{Introduction}

Fallopia multiflora (Thunberg) Haraldson (Polygonaceae), synonym Polygonum multiflorum Thunb., is an important medicinal plant in Oriental medicine. It is grown for various medicinal values ranging from bowel relaxation, antiaging, hair loss prevention, increasing sexual vigour, treatment of high cholesterol, high blood pressure, and inflammation [1]. Previous phytochemical investigations have revealed the presence of stilbenes and anthraquinones as major components in F. multiflora [2]. 2,3,5,4'-Tetrahydroxystilbene-2-O- $\beta$-D-glucopyranoside, emodin, and physcion are used as main markers for quality control of F. multiflora materials and related products [3]. Flavonoids and proanthocyanidins were also found in this plant $[3,4]$. Several naphtolic compounds including torachrysone-8-O$\beta$-D-glucopyranoside, torachrysone-8-O- $\left(6^{\prime}\right.$-O-acetyl) $\beta$-Dglucopyranoside, and torachrysone-8-O-(6'-O-galloyl) $-\beta$-Dglucoside were also reported [3]. In the present study, a phytochemical investigation of the Fallopia multiflora roots led to the isolation of two new (1 and $\mathbf{3}$ ) and nine known compounds (Figure 1).

\section{Experimental}

2.1. General. Thin layer chromatography was performed using precoated Kieselgel 60 F254 (Merck) and visualized by UV light $254 \mathrm{~nm}$ and $10 \% \mathrm{H}_{2} \mathrm{SO}_{4}$ reagent under heating. Column chromatography was performed using silica gel 60 (Merck, 70-230 mesh). Optical rotations were read on a JASCO P-2000 digital polarimeter. NMR experiments were performed on a Bruker AM500 FT-NMR spectrometer. The HR-ESI-MS data were obtained from a LTQ Orbitrap XL Mass Spectrometer (Thermo Scientific). GC analysis was carried out on an Agilent 7890B GC System using a column SPB-1 $(0.25 \mathrm{~mm} \times 30 \mathrm{~m})$, detector FID, column temp. $210^{\circ} \mathrm{C}$, injector temperature $270^{\circ} \mathrm{C}$, detector temperature $300^{\circ} \mathrm{C}$, and He carrier gas. 


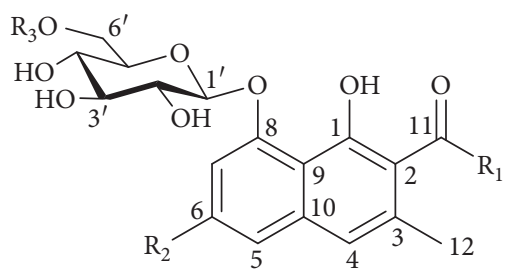

1: $\mathrm{R}_{1}=\mathrm{CH}_{3}, \mathrm{R}_{2}=\mathrm{OH}, \mathrm{R}_{3}=$ apiofuranoside

2: $\mathrm{R}_{1}=\mathrm{CH}_{3}, \mathrm{R}_{2}=\mathrm{OMe}, \mathrm{R}_{3}=\mathrm{H}$

3: $\mathrm{R}_{1}=\mathrm{OH}, \mathrm{R}_{2}=\mathrm{OMe}, \mathrm{R}_{3}=\mathrm{H}$
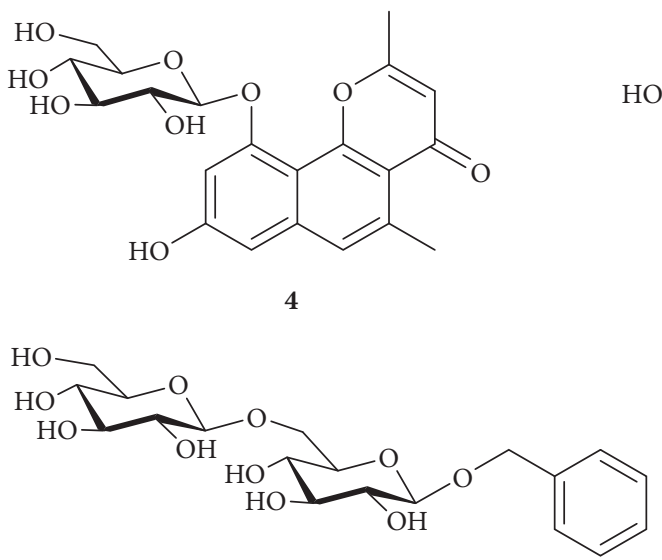

10<smiles>[R20]c1cc(OCC)c2c(c1)C(=O)c1cc(C)cc(O)c1C2=O</smiles>

5: $\mathrm{R}_{1}=\mathrm{R}_{2}=\mathrm{H}$

6: $\mathrm{R}_{1}=\mathrm{H}, \mathrm{R}_{2}=\mathrm{Glc}$

7: $\mathrm{R}_{1}=\mathrm{CH}_{3}, \mathrm{R}_{2}=$ glucopyranoside

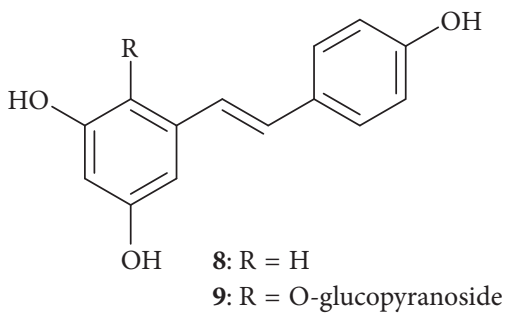<smiles>Oc1cc(O)c2c(c1)O[C@H](c1ccc(O)c(O)c1)[C@H](O)C2</smiles>

11

FIGURE 1: The structure of compounds 1-11 isolated from Fallopia multiflora.

2.2. Plant Material. The roots of F. multiflora were collected in Dong Van commune, Ha Giang province, Vietnam, on October 2014 and identified by Dr. Nguyen The Cuong, Institute of Ecology and Biological Resources, VAST. Voucher specimens (HaGiang-03) have been deposited at the herbarium of the Institute of Ecology and Biological Resources.

2.3. Extraction and Isolation. The air-dried and powdered roots of $F$. multiflora $(3.5 \mathrm{~kg}$ ) were extracted with methanol $(6 \mathrm{~L} \times 3$ times $)$ in a sonic bath for $30 \mathrm{~min}$ at $40^{\circ} \mathrm{C}$. The combined extracts were evaporated under reduced pressure to give crude extract $(430.0 \mathrm{~g})$, which was then resuspended in water $(3 \mathrm{~L})$ and successively partitioned by $n$-hexane and ethyl acetate (each $1 \mathrm{~L} \times 3$ times) to obtain $n$-hexane $(51.7 \mathrm{~g}$ ) and ethyl acetate $(214.5 \mathrm{~g})$ residues, respectively. The aqueous solution was passed through a Diaion HP-20 column and eluted by 0,50 , and $100 \%$ methanol in water to give three fractions W1-3. Fraction W3 was chromatographed on a silica gel column using mobile phase of a gradient of $0-100 \%$ methanol in dichloromethane to obtain seven fractions F1-7. Fraction F4 was purified by a silica gel column chromatography eluting with dichloromethane-methanol $6: 1$ (v/v) to yield 9 (457.0 mg). Fraction F5 was passed through a C-18 column using acetone-water $2: 3(\mathrm{v} / \mathrm{v})$ as eluent to obtain 3 ( $8.0 \mathrm{mg})$. Compounds 1 (12.8 mg), 2 (5.4 mg), and 7 ( $4.5 \mathrm{mg}$ ) were purified from F6 by a silica gel column eluted by dichloromethane-methanol 6:1 (v/v). Repeated column chromatography using C18 and Sephadex LH-20 stationary phases were applied for fraction F7 to afford compounds 6 $(6.8 \mathrm{mg})$ and $10(6.0 \mathrm{mg})$. The ethyl acetate residue was fractionated by a silica gel column eluted by a gradient of $0-100 \%$ methanol in dichloromethane to obtain five fractions E1-5. Fraction E3 was subjected to a silica gel column eluted by $n$-hexane-ethyl acetate $5: 1(\mathrm{v} / \mathrm{v})$ to obtain compounds 5 (90.4 mg). Compound 8 (3.4 mg) was purified from E4 by a Sephadex LH-20 column using methanol-water 1:1 (v/v). Similar Sephadex LH-20 column was applied for E5 to afford 4 (28.1 mg) and 11 (90.8 mg).

2.3.1. 6-Hydroxymusizin 8-O- $\alpha$-D-apiofuranosyl- $(1 \rightarrow 6)-\beta-D$ glucopyranoside (1). Yellow powder; $[\alpha]_{\mathrm{D}}{ }^{24}=+12.6^{\circ}(c=0.05$, $\left.\mathrm{CH}_{3} \mathrm{OH}\right) ;{ }^{1} \mathrm{H}$ and ${ }^{13} \mathrm{C}$ NMR see Table 1; HR-ESI-MS: $\mathrm{m} / z$ $549.1578[\mathrm{M}+\mathrm{Na}]^{+}$(calcd. 549.1584 for $\mathrm{C}_{24} \mathrm{H}_{30} \mathrm{NaO}_{13}$ ).

2.3.2. 6-Methoxy-3-methyl-1,6,8-trihydroxy-2-naphthoic acid 8-O- $\beta$-D-glucopyranoside (2). Pale-yellow powder; $[\alpha]_{\mathrm{D}}{ }^{24}=$ $+23.4^{\circ}\left(c=0.05, \mathrm{CH}_{3} \mathrm{OH}\right) ;{ }^{1} \mathrm{H}$ and ${ }^{13} \mathrm{C}$ NMR see Table 1 ; HRESI-MS: $m / z \quad 433.1110 \quad[\mathrm{M}+\mathrm{Na}]^{+}$(calcd. 433.1111 for $\left.\mathrm{C}_{19} \mathrm{H}_{22} \mathrm{NaO}_{10}\right)$.

2.3.3. Acid Hydrolysis and Sugar Identification. The compounds 1 and 3 (each $1 \mathrm{mg}$ ) were individually dissolved in $1 \mathrm{ml}$ of dioxane $/ 1 \mathrm{~N} \mathrm{HCl}(1: 1 \mathrm{v} / \mathrm{v})$ and heated at $80^{\circ} \mathrm{C}$ for $3 \mathrm{~h}$. The acidic solution was neutralized with silver carbonate and extracted with $\mathrm{CH}_{2} \mathrm{Cl}_{2}$. The aqueous layer was concentrated to dryness using nitrogen gas. The residue was then dissolved 
TABLE 1: NMR data of compounds 1 and 3.

\begin{tabular}{|c|c|c|c|c|}
\hline \multirow{2}{*}{ Number } & \multicolumn{2}{|l|}{1} & \multicolumn{2}{|l|}{3} \\
\hline & $\delta_{\mathrm{H}}$ (mult., $J$ in $\mathrm{Hz}$ ) & $\delta_{\mathrm{C}}$ & $\delta_{\mathrm{H}}$ (mult., $J$ in $\mathrm{Hz}$ ) & $\delta_{\mathrm{C}}$ \\
\hline 1 & - & 154.0 & - & 153.8 \\
\hline 2 & - & 123.2 & - & 123.9 \\
\hline 3 & - & 135.2 & - & 135.5 \\
\hline 4 & $6.91(1 \mathrm{H}, \mathrm{s})$ & 119.6 & $7.05(1 \mathrm{H}, \mathrm{s})$ & 120.3 \\
\hline 5 & $6.72(1 \mathrm{H}, \mathrm{d}, 2.0)$ & 105.5 & $6.84(1 \mathrm{H}, \mathrm{d}, 2.0)$ & 102.5 \\
\hline 6 & - & 158.1 & - & 160.4 \\
\hline 7 & $7.00(2 \mathrm{H}, \mathrm{d}, 2.0)$ & 104.9 & $7.03(1 \mathrm{H}, \mathrm{d}, 2.0)$ & 104.4 \\
\hline 8 & - & 157.4 & - & 157.2 \\
\hline 9 & - & 109.7 & - & 110.3 \\
\hline 10 & - & 139.3 & - & 139.1 \\
\hline 11 & - & 208.2 & - & 171.0 \\
\hline 12 & $2.28(3 \mathrm{H}, \mathrm{s})$ & 20.2 & $2.30(3 \mathrm{H}, \mathrm{s})$ & 20.2 \\
\hline $\mathrm{OCH}_{3}$ & - & - & $3.88(3 \mathrm{H}, \mathrm{s})$ & 55.9 \\
\hline $\mathrm{COCH}_{3}$ & $2.60(3 \mathrm{H}, \mathrm{s})$ & 32.6 & - & - \\
\hline $1^{\prime}$ & $5.07(1 \mathrm{H}, \mathrm{d}, 7.5)$ & 104.3 & $5.12(1 \mathrm{H}, \mathrm{d}, 7.5)$ & 104.1 \\
\hline $2^{\prime}$ & $3.57(1 \mathrm{H}, \mathrm{m})$ & 74.9 & $3.58(1 \mathrm{H}, \mathrm{m})$ & 74.9 \\
\hline $3^{\prime}$ & $3.51(1 \mathrm{H}, \mathrm{t}, 8.5)$ & 78.1 & $3.54(1 \mathrm{H}, \mathrm{m})$ & 78.1 \\
\hline $4^{\prime}$ & $3.45(1 \mathrm{H}, \mathrm{m})$ & 71.5 & $3.45(1 \mathrm{H}, \mathrm{m})$ & 71.3 \\
\hline $5^{\prime}$ & $3.68(1 \mathrm{H}, \mathrm{m})$ & 77.6 & $3.56(1 \mathrm{H}, \mathrm{m})$ & 78.8 \\
\hline $6^{\prime}$ & $3.70(1 \mathrm{H}, \mathrm{m}), 4.12(1 \mathrm{H}, \mathrm{d}, 9.5)$ & 68.6 & $3.96(1 \mathrm{H}, \mathrm{dd}, 12.5,2.5), 3.77(1 \mathrm{H}, \mathrm{dd}, 12.5,5.5)$ & 62.4 \\
\hline $1^{\prime \prime}$ & $5.05(1 \mathrm{H}, \mathrm{d}, 2.5)$ & 111.0 & - & - \\
\hline $2^{\prime \prime}$ & $4.01(1 \mathrm{H}, \mathrm{d}, 2.5)$ & 78.1 & - & - \\
\hline $3^{\prime \prime}$ & - & 80.5 & - & - \\
\hline $4^{\prime \prime}$ & $3.80(1 \mathrm{H}, \mathrm{d}, 9.5), 4.04(1 \mathrm{H}, \mathrm{d}, 9.5)$ & 75.1 & - & - \\
\hline $5^{\prime \prime}$ & $3.36(2 \mathrm{H}, \mathrm{m})$ & 65.7 & - & - \\
\hline
\end{tabular}

in $0.1 \mathrm{~mL}$ of pyridine, followed by addition of $0.1 \mathrm{~mL}$ of $0.06 \mathrm{M}$ L-cysteine methyl ester hydrochloride in pyridine. After heating at $60^{\circ} \mathrm{C}$ for $2 \mathrm{~h}, 0.1 \mathrm{~mL}$ trimethylsilylimidazole was then added to the solution, followed by heating at $60^{\circ} \mathrm{C}$ for another $1.5 \mathrm{~h}$. The dried product was partitioned with $n$ hexane and water $(0.1 \mathrm{~mL}$ each), and the organic layer was analyzed by GC. D-glucose and D-apiose were detected at 14.15 and $4.61 \mathrm{~min}$, respectively.

\section{Results and Discussion}

Compound 1 was obtained as a yellow powder with the molecular formula $\mathrm{C}_{24} \mathrm{H}_{30} \mathrm{O}_{13}$, which was established from the HR-ESI-MS data with the ion peak at $\mathrm{m} / z 549.1578$ $[\mathrm{M}+\mathrm{Na}]^{+}$. The ${ }^{1} \mathrm{H}$ NMR spectrum of $\mathbf{1}$ showed signals characteristic for an aromatic proton at $\delta_{\mathrm{H}} 6.91(1 \mathrm{H}, \mathrm{s}, \mathrm{H}-4)$, a pair of meta-coupled aromatic protons at $\delta_{\mathrm{H}} 6.72(1 \mathrm{H}$, $\mathrm{d}, J=2.0 \mathrm{~Hz}, \mathrm{H}-5)$ and $7.00(2 \mathrm{H}, \mathrm{d}, J=2.0 \mathrm{~Hz}, \mathrm{H}-7)$, two downfielded methyl groups at $\delta_{\mathrm{H}} 2.28\left(3 \mathrm{H}, \mathrm{s}, 3-\mathrm{CH}_{3}\right), 2.60$ $\left(3 \mathrm{H}, \mathrm{s}, \mathrm{CH}_{3} \mathrm{CO}\right)$, and two anomeric protons at $\delta_{\mathrm{H}} 5.07$ $\left(1 \mathrm{H}, \mathrm{d}, J=7.5 \mathrm{~Hz}, \mathrm{H}-1^{\prime}\right)$ and $5.05\left(1 \mathrm{H}, \mathrm{d}, J=2.5 \mathrm{~Hz}, \mathrm{H}-1^{\prime \prime}\right)$. The coupling constants indicated the $\beta(J=7.5 \mathrm{~Hz})$ and $\alpha(J=2.5 \mathrm{~Hz})$ conformations of the glycosyl units. Analysis of the ${ }^{13} \mathrm{C}$ NMR and HSQC spectra of 1 revealed the presence of an aromatic methyl at $\delta_{\mathrm{C}} 20.2\left(3-\mathrm{CH}_{3}\right)$, an acetyl group $\left(\delta_{\mathrm{C}} 208.2\right.$ and 32.6$)$ and ten aromatic signals of a naphthalene skeleton (Table 1$)$. In addition, an apiofuranosyl-( $1 \rightarrow 6)$ glucopyranoside moiety was recognized [5]. Acid hydrolysis and GC analysis led to the identification of D-glucose and $\mathrm{D}$-apiose. Comparison with reported data suggested the skeleton was 6-hydroxymusizin [6]. The HMBC correlations of 1 (Figure 2) confirmed that the glucose moiety attached to C-8 and the apiose unit attached to C- $6{ }^{\prime}$. From these findings, the structure of compound $\mathbf{1}$ was determined to be 6-hydroxymusizin $8-O-\alpha$-D-apiofuranosyl$(1 \rightarrow 6)$ - $\beta$-D-glucopyranoside.

Compound 3 was obtained as a pale-yellow powder. Its molecular formula was determined as $\mathrm{C}_{19} \mathrm{H}_{22} \mathrm{O}_{10}$ on the basis of the HR-ESI-MS that showed the ion peak at $\mathrm{m} / z$ $433.1110[\mathrm{M}+\mathrm{Na}]^{+}$. The ${ }^{1} \mathrm{H}$ NMR spectrum of 3 displayed resonances for an aromatic proton $\left[\delta_{\mathrm{H}} 7.05(1 \mathrm{H}, \mathrm{s}, \mathrm{H}-4)\right]$, two meta-coupled protons $\left[\delta_{\mathrm{H}} 6.84(1 \mathrm{H}, \mathrm{d}, J=2.0 \mathrm{~Hz}, \mathrm{H}-5)\right.$ and $7.03(2 \mathrm{H}, \mathrm{d}, J=2.0 \mathrm{~Hz}, \mathrm{H}-7)]$, an aromatic methyl $\left[\delta_{\mathrm{H}}\right.$ $\left.2.28\left(3 \mathrm{H}, \mathrm{s}, 3-\mathrm{CH}_{3}\right)\right]$, a methoxy group $\left[\delta_{\mathrm{H}} 3.88(3 \mathrm{H}, \mathrm{s}\right.$, $\left.\left.6-\mathrm{OCH}_{3}\right)\right]$, and a $\beta$-anomeric proton of a sugar moiety $\left[\delta_{\mathrm{H}}\right.$ $5.12\left(1 \mathrm{H}, \mathrm{d}, J=8.0 \mathrm{~Hz}, \mathrm{H}-1^{\prime}\right)$. The ${ }^{13} \mathrm{C}$ NMR and HSQC spectra of 3 showed the signals characteristic for a methoxy, an aromatic methyl, a glucose moiety and a naphthalene skeleton. These data were almost identical to that of torachrysone 8-O- $\beta$-D-glucopyranoside (2) except for the replacement of the acetyl group by a carboxylic group $\left(\delta_{\mathrm{C}}\right.$ 171.0) at C-2 $[7,8]$. The HMBC correlations confirmed the position of the methoxy and glucose groups at C-6 and C-8, respectively (Figure 2). Acid hydrolysis and GC analysis led to the identification of D-glucose. Therefore, compound 3 was deduced as 6-methoxy-3-methyl-1,6,8-trihydroxy-2naphthoic acid $8-O-\beta$-D-glucopyranoside.

By means of spectroscopic methods and in comparison with the reported data, the structure of the known compounds was identified as torachrysone 8-O- $\beta$-D-glucopyranoside (2), 

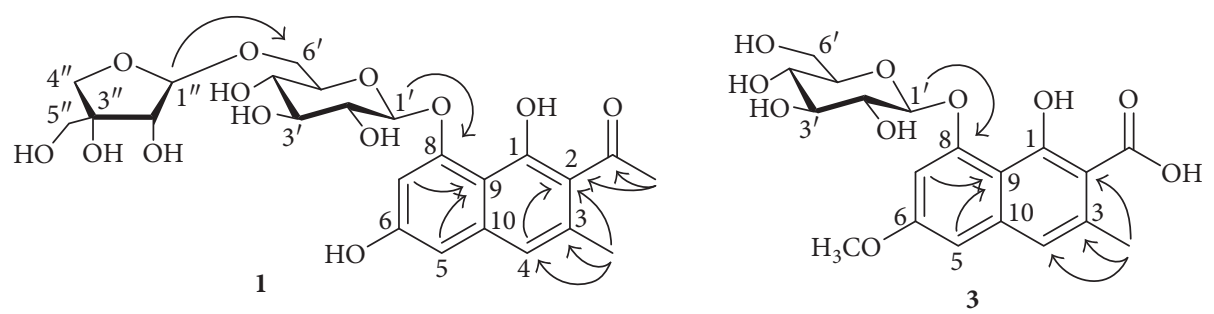

FIgURE 2: Key HMBC correlations of 1 and 3.

pleuropyrone A (4), emodin (5), emodin 8-O-glucopyranoside (6), physcionin (7), resveratrol (8), 2,3,5,4'-tetrahydroxy stilbene-2-O- $\beta$-glucoside (9), benzyl gentiobioside (10), and catechin (11). Naphtolic derivatives including torachrysone 8-O- $\beta$-D-glucopyranoside (2) have been identified in the Polygonaceae [3,8-12] and other families such as Fabaceae, Rhamnaceae, Araliaceae, and Euphorbiaceae [13-16]. All those compounds possessed a hydroxyl group at C-1, an acetyl group at C-2, and a methyl at C-3 in the naphthalene skeleton. However, compound 3 bearing a carboxylic group instead of an acetyl group in the same skeleton has not been found previously from the natural source. Thus, compound 3 could be considered as a specific chemotaxonomic marker for F. multiflora. The anthraquinones and stilbenes including emodin (5), emodin 8-O-glucopyranoside (6) and 2,3,5,4'-tetrahydroxystilbene-2-O- $\beta$-glucoside (9) are main constituents of $F$. multiflora and have been listed as chemical markers for quality control of this plant material $[2,17]$. The present study reports for the first time the occurrence of benzyl gentiobioside (10) in Polygonaceae, which can be used as a characteristic chemical constituent of F. multiflora in contrast to other species belonging to the genus Fallopia and family Polygonaceae.

\section{Conclusion}

Chemical investigation of the roots of Fallopia multiflora led to the isolation of eleven phenolic compounds including 8-O$\alpha$-D-apiofuranosyl-(1 $\rightarrow 6)-\beta$-D-glucopyranoside $(\mathbf{1}), 8-\mathrm{O}-\beta$-Dglucopyranoside (2), 6-methoxy-3-methyl-1,6,8-trihydroxy-2naphthoic acid 8-O- $\beta$-D-glucopyranoside (3), torachrysone pleuropyrone A (4), emodin (5), emodin 8-O-glucopyranoside (6), physcionin (7), resveratrol (8), 2,3,5,4'-tetrahydroxystilbene-2-O- $\beta$-glucoside (9), benzyl gentiobioside (10), and catechin (11). Compounds 1 and 3 were elucidated as new naphtolic glycosides. Of note, compound 3 bearing a carboxylic group instead of an acetyl group in the same skeleton has not been found previously from the natural source.

\section{Data Availability}

The authors confirm that the data supporting the findings of this study are available within the article and its supplementary materials.

\section{Conflicts of Interest}

The authors declare that there are no conflicts of interest regarding the publication of this paper.

\section{Acknowledgments}

This work is supported by the Vietnam Academy of Science and Technology (Grant code VAST.UDCN.05/14-16).

\section{Supplementary Materials}

HR-ESI-MS and NMR spectra of compounds $\mathbf{1}$ and $\mathbf{3}$. (Supplementary Materials)

\section{References}

[1] V. C. Vo, Dictionary of Vietnamese Medicinal Plants, Vol. I, Medicine Publisher, Hanoi, Vietnam, 2012.

[2] T. H. Wang, J. Zhang, X. H. Qiu, J. Q. Bai, Y. H. Gao, and W. Xu, "Application of ultra-high-performance liquid chromatography coupled with LTQ-Orbitrap mass spectrometry for the qualitative and quantitative analysis of Polygonum multiflorum Thumb. and its processed products," Molecules, vol. 21, no. 1, p. 40, 2015.

[3] L. Lin, B. Ni, H. Lin et al., "Traditional usages, botany, phytochemistry, pharmacology and toxicology of Polygonum multiflorum Thunb.: a review," Journal of Ethnopharmacology, vol. 159, pp. 158-183, 2015.

[4] H. Wang, L. Song, S. Feng et al., "Characterization of proanthocyanidins in stems of Polygonum multiflorum Thunb as strong starch hydrolase inhibitors," Molecules, vol. 18, no. 2, pp. 2255-2265, 2013.

[5] B. Y. Yang, J. T. Guo, Z. Y. Li et al., "New thymoquinol glycosides and neuroprotective dibenzocyclooctane lignans from the rattan stems of Schisandra chinensis," Chemistry \& Biodiversity, vol. 13, no. 9, pp. 1118-1125, 2016.

[6] M. Horikawa, T. Noguchi, S. Takaoka, M. Kawase, M. Sato, and T. Tsunoda, "Furanaphin: a novel naphtho[2,3-c]furan-4 $(1 \mathrm{H})$-one derivative from the aphid Aphis spiraecola Patch," Tetrahedron, vol. 60, no. 5, pp. 1229-1234, 2004.

[7] Y. N. Sun, L. Cui, W. Li et al., "Promotion effect of constituents from the root of Polygonum multiflorum on hair growth," Bioorganic \& Medicinal Chemistry Letters, vol. 23, no. 17, pp. 4801-4805, 2013.

[8] M. Tsuboi, M. Minami, G. J. Nonaka, and I. Nishioka, "Studies on rhubarb (Rhei rhizoma). IV. Naphthalene glycosides," Chemical \& Pharmaceutical Bulletin, vol. 25, no. 10, pp. 2708-2712, 1977.

[9] O. Demirezer, A. Kuruuzum, I. Bergere, H. J. Schiewe, and A. Zeeck, "Five naphthalene glycosides from the roots of Rumex patientia," Phytochemistry, vol. 56, no. 4, pp. 399-402, 2001.

[10] L. Krenn, A. Presser, R. Pradhan et al., "Sulfemodin 8-O-betaD-glucoside, a new sulfated anthraquinone glycoside, and antioxidant phenolic compounds from Rheum emodi," 
Journal of Natural Products, vol. 66, no. 8, pp. 1107-1109, 2003.

[11] H. X. Liang, H. Q. Dai, H. A. Fu et al., "Bioactive compounds from Rumex plants,” Phytochemistry Letters, vol. 3, no. 4, pp. 181-184, 2010.

[12] D. Tang, J. X. Zhu, A. G. Wu et al., "Pre-column incubation followed by fast liquid chromatography analysis for rapid screening of natural methylglyoxal scavengers directly from herbal medicines: case study of Polygonum cuspidatum," Journal of Chromatography A, vol. 1286, pp. 102-110, 2013.

[13] J. Lemli, S. Toppet, J. Cuveele, and G. Janssen, "Naphthalene glycosides in Cassia senna and Cassia angustifolia," Planta Medica, vol. 43, no. 9, pp. 11-17, 1981.

[14] C. N. Lin and B. L. Wei, "Anthraquinone and naphthalene glycosides from Rhamnus nakaharai," Phytochemistry, vol. 33, no. 4, pp. 905-908, 1993.

[15] N. Li, H. S. Lee, N. Zhang et al., "Two new diphenyl ethers from Acanthopanax senticosus (Rupr. \& Maxim.) Harms with PTP1B inhibitory activity," Phytochemistry Letters, vol. 13, pp. 286-289, 2015.

[16] C. H. Iwuji and A. Nwafor, "Phytochemical identification in the chloroform fraction of aqueous-methanol extract of Cnidoscolus aconitifolius leaves," British Journal of Pharmaceutical Research, vol. 5, no. 6, pp. 437-441, 2015.

[17] Y. Zhao, C. P. Kao, Y. S. Chang, and Y. L. Ho, "Quality assessment on Polygoni Multiflori Caulis using HPLC/UV/MS combined with principle component analysis," Chemistry Central Journal, vol. 7, no. 1, p. 106, 2013. 

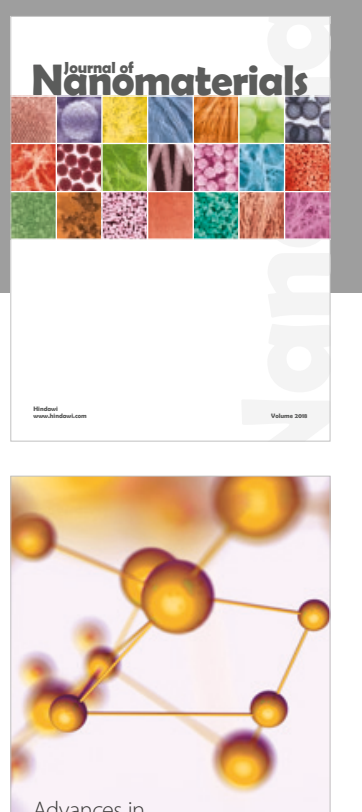

Physical Chemistry
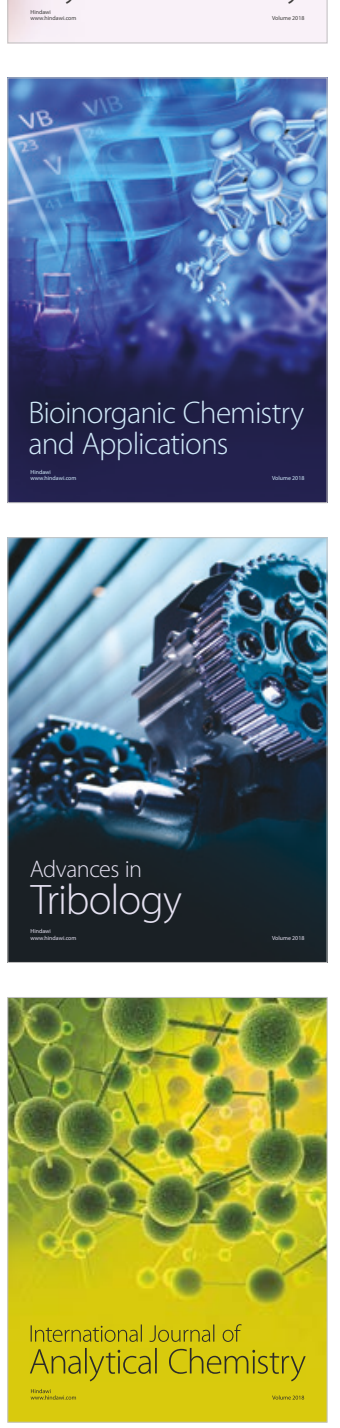

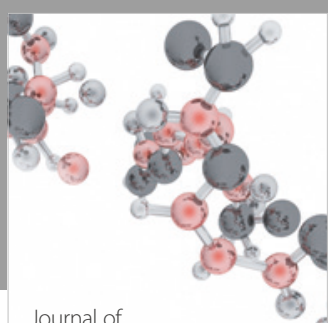

Analytical Methods

in Chemistry

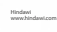

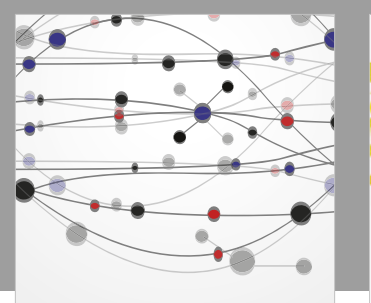

The Scientific World Journal

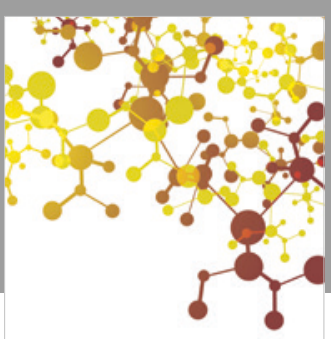

Journal of

Applied Chemistry
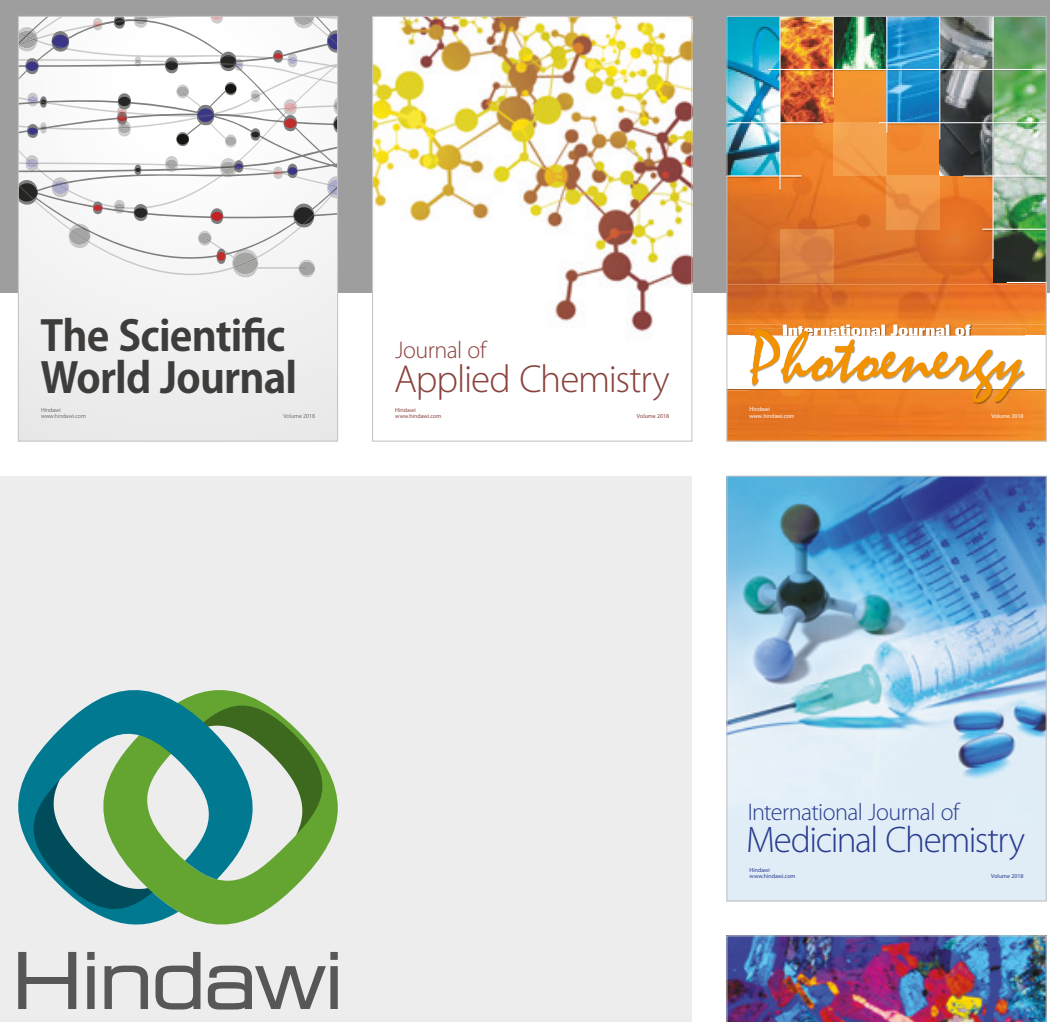

Submit your manuscripts at

www.hindawi.com
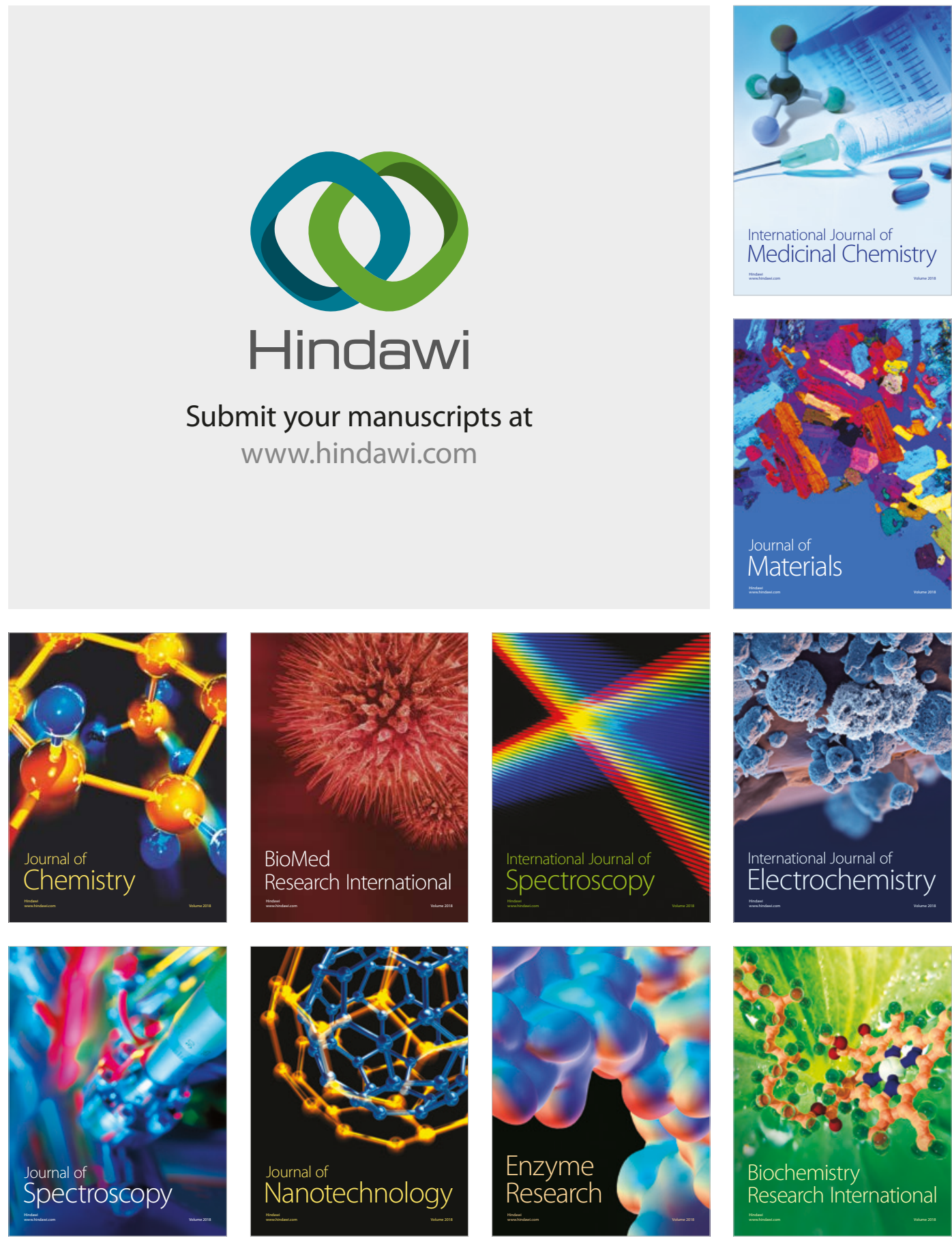
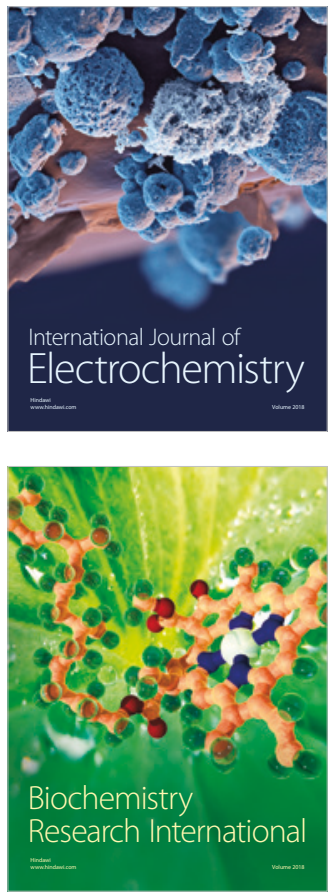